\title{
A Fuzzy Non-radial Data Envelopment Model: A Case Study of Commercial Banks
}

\author{
Shaobo Yuan ${ }^{1, a^{*}}$ \\ ${ }^{1}$ Shanghai University, Shangda road 99, Shanghai,China \\ acrystal_y@hotmail.com
}

Keywords: SBM, Fuzzy method, Evaluation algorithm.

Abstract. DEA method is widely accepted in evaluation of financial efficiency. While the efficiency issues with uncertain data can not be solved easilily. In this paper a fuzzy non-radial data envelopment model is proposed to deal with the aforementioned issues. An empirical study of commercial banks in China is also supplied, to test the merits of evaluation algorithm in this paper.

\section{Introduction}

Currently, financial industry has become essential contributor of national economies.In year 2014, finance industry contribute $5 \%$ to the total $7.4 \%$ increase of GDP. While, there still exist several shortcomings in the production and operation processes like lack of innovation in finance product and higher bad loan ratio ${ }^{[1]}$. Thus, in order to improve the conditions of this industry, the effciency evaluation should be stressed.

To acquire reasonable efficiency result, the collection of accurate data is necessary. Unfortunately, the realistic collections always consist of uncertain or interval data values. To solve this problem, we develop slack-based model with fuzzy method.

\section{Basic Theory}

Data envelopment analysis (DEA) is a widely-accepted non-parametric method for efficiency evaluation of decision making units (DMUs) ${ }^{[2]}$. It begins with the CCR model introduced by Charnes as the first DEA model. A definition of efficiency in this model is the ratio of the weighted sum of outputs divided by weighted sum of inputs. A DMU is an entity responsible for converting inputs into outputs and whose pergraphances are to be evaluated. In DEA models it is important to use non-Archimedean constant for the weights, which ensures their positivity. It is connected with pseudo-efficiency of the DMUs, in which case the efficency score does not reflect the real efficiency of the units evaluated. Considering $n$ DMUs, each of them characterized by $m$ inputs and s outputs and denote a semi-positive column vector of inputs of the $\mathrm{j}^{\text {th }} \mathrm{DMU}$ as $X_{j}=\left(x_{1 j}, x_{2 j}, \ldots, x_{m j}\right)$, and the output is $Y_{j}=\left(y_{1 j}, y_{2 j}, \ldots y_{s j}\right)$ $(\mathrm{j}=1,2, \ldots \mathrm{n})$

By considering no-radial efficiency of DMUs put forward by Tone (2001), Slack-based Model(SBM) can be shown in Eq.1 :

$$
\begin{aligned}
\text { Min } \rho_{k} & =\frac{1-\frac{1}{m} \sum_{i=1}^{m} \frac{s_{i}^{-}}{x_{i k}}}{1+\frac{1}{s} \sum_{r=1}^{s} \frac{s_{r}^{+}}{y_{r k}}} \\
\text { s.t. } x_{i k} & =\sum_{j=1}^{n} x_{i j} \lambda_{j}+s_{i}^{-}, i=1,2, \ldots m \\
y_{r k} & =\sum_{j=1}^{n} y_{r j} \lambda_{j}-s_{r}^{+}, r=1,2, \ldots s
\end{aligned}
$$




$$
\begin{gathered}
\sum_{j=1}^{n} \lambda_{j}=1 \\
\lambda_{j} \geq 0, j=1, \ldots n \\
s_{i}^{-} \geq 0, s_{r}^{+} \geq 0
\end{gathered}
$$

In this model, $\lambda_{j}$ is the weight, and $s_{i}^{-}$and $s_{r}^{+}$are the slack amount. After transforming the model into linear programming model, we can easily discover that when $\rho_{k}=1, s_{i}^{-}=0, s_{r}^{+}=0$, the optimum solution happens. That means DMU is efficient when the overdose inputs and insufficient outputs do not happens together.

\section{Fuzzy Slack-Based Model}

We use non-radial SBM model to do fuzzy expansion cause this model add slack quantities of input and output into objective function and constraint function, which confirms the evaluation of fuzzy DMU much reasonable ${ }^{[3]}$.

The SBM mode is constructed in Eq.2:

$\operatorname{Min} \bar{\rho}_{k}=q-\frac{1}{m} \sum_{i=1}^{m} \frac{s_{1}^{-}}{x_{i k}}$

s.t. $q+\frac{1}{s} \sum_{r=1}^{s} \frac{s_{r}^{+}}{y_{r k}}=1$

$$
\begin{aligned}
& q \tilde{x}_{r k}=\sum_{j=1}^{n} \tilde{x}_{r j} \lambda_{j}^{\prime}+S_{r}^{-} \mathrm{i}=1, \ldots, \mathrm{m} \\
& q \tilde{y}_{r k}=\sum_{j=1}^{n} \tilde{y}_{r j} \lambda_{j}^{\prime}-S_{r}^{+} \mathrm{r}=1, \ldots, \mathrm{n} \\
& \sum_{j=1}^{n} \lambda_{j}^{\prime}=q, q>0, \lambda_{j}^{\prime} \geq 0 \mathrm{j}=1, \ldots \mathrm{n} \\
& S_{1}^{-} \geq 0, S_{1}^{-}=q s_{1}^{-} \\
& S_{r}^{+} \geq 0, S_{r}^{+}=q S_{r}^{+}, \lambda_{j}^{\prime}=q \lambda_{j}
\end{aligned}
$$

We suppose inputs are triangular fuzzy numbers as $X_{i j}=\left(x_{i j}^{L}, x_{i j}^{M}, x_{i j}^{U}\right)$, while the outputs are $Y_{i j}=\left(y_{i j}^{L}, y_{i j}^{M}, y_{i j}^{U}\right)^{[4]}$. Given level $\alpha$, then the cut set is in Eq.3 and Eq.4 :

$$
\begin{aligned}
& \left(X_{i j}\right)_{\alpha}=\left\{x_{i j} \in S\left(\tilde{x_{i j}}\right) \mid \mu_{x_{i j}}\left(x_{i j}\right) \geq \alpha\right\}, \forall j . i \\
& \left(Y_{r j}\right)_{\alpha}=\left\{y_{r j} \in S\left(\tilde{y_{r j}}\right) \mid \mu_{\tilde{y}_{r j}}\left(y_{r j}\right) \geq \alpha\right\}, \forall j, r
\end{aligned}
$$

Cause of fuzzy the inputs and outputs changes by change of $\alpha$, the $\alpha$ cut set can be presented as an interval form as Eq.5 and Eq.6:

$$
\begin{aligned}
& \left(X_{i j}\right)_{\alpha}=\left\{x_{i j} \in S\left(\tilde{x_{i j}}\right) \mid \mu_{\tilde{r}_{i j}}\left(x_{i j}\right) \geq \alpha\right\} \\
& =\left[\min _{x_{i j}}\left\{x_{i j} \in S\left(\tilde{x_{i j}}\right) \mid \mu_{\tilde{x}_{i j}}\left(x_{i j}\right) \geq \alpha\right\}, \max _{x_{i j}}\left\{x_{i j} \in S\left(\tilde{x_{i j}}\right) \mid \mu_{\tilde{x}_{i j}}\left(x_{i j}\right) \geq \alpha\right\}\right]
\end{aligned}
$$




$$
\begin{aligned}
& \left(Y_{i j}\right)_{\alpha}=\left\{y_{r j} \in S\left(\tilde{y_{r j}}\right) \mid \mu_{y_{r j}}\left(y_{r j}\right) \geq \alpha\right\} \\
& =\left[\min _{y_{r j}}\left\{y_{r j} \in S\left(\tilde{y_{r j}}\right) \mid \mu_{y_{r j}}\left(y_{r j}\right) \geq \alpha\right\}, \max _{y_{r j}}\left\{y_{r j} \in S\left(\tilde{y_{r j}}\right) \mid \mu_{y_{r j}}\left(y_{r j}\right) \geq \alpha\right\}\right]
\end{aligned}
$$

We define inputs as triangular fuzzy numbers $X_{i j}=\left(x_{i j}^{L}, x_{i j}^{M}, x_{i j}^{U}\right)$, define outputs as $Y_{i j}=\left(y_{i j}^{L}, y_{i j}^{M}, y_{i j}^{U}\right)$, with given levels, the cut sets are shown in Eq.7and Eq.8:

$$
\begin{aligned}
& \left(X_{i j}\right)_{\alpha}=\left[x_{i j}^{L}+\alpha\left(x_{i j}^{M}-x_{i j}^{L}\right), x_{i j}^{U}-\alpha\left(x_{i j}^{U}-x_{i j}^{M}\right)\right] \\
& \left(Y_{r j}\right)_{\alpha}=\left[y_{r j}^{L}+\alpha\left(y_{r j}^{M}-y_{r j}^{L}\right), y_{r j}^{U}-\alpha\left(y_{r j}^{U}-y_{r j}^{M}\right)\right]
\end{aligned}
$$

According to Zadeh's Extension principle in $1978^{[5]}$, membership function of DMU's efficiency is defined in Eq.9:

$$
\mu_{\tilde{E}_{k}}(z)=\sup _{x, y} \min \left\{\mu_{\tilde{x}_{i j}}\left(x_{i j}\right), \mu_{\tilde{y}_{r j}}\left(y_{r j}\right), \forall j, r, i \mid z=E_{k}(x, y)\right\}
$$

In the equation $E_{k}(x, y)$ is the $D M U_{k}$ efficiency caculated by traditional SBM model.

The upper and lower of $\mu_{\tilde{E}_{k}}$ is acquired with programming below in Eq.10:

Min $q-\frac{1}{m} \sum_{i=1}^{m} \frac{S_{i}^{-}}{x_{i k}}$

s.t. $q+\frac{1}{s} \sum_{r=1}^{s} \frac{S_{r}^{+}}{y_{r k}}=1$

$$
\begin{aligned}
& q x_{i k}=\sum_{j=1}^{n} x_{i j} \lambda_{j}^{\prime}+S_{i}^{-}, i=1, \ldots m \\
& q y_{r k}=\sum_{j=1}^{n} y_{r j} \lambda_{j}^{\prime}-S_{r}^{+}, r=1, \ldots S \\
& \sum_{j=1}^{n} \lambda_{j}^{\prime}=q, q>0 \\
& \lambda_{j}^{\prime} \geq 0, j=1, \ldots n \\
& S_{r}^{+} \geq 0, S_{i}^{-} \geq 0
\end{aligned}
$$

We suppose the programming result is $Z$, then $\mu_{\tilde{E}_{k}}$ 's $\alpha$ cut set 's upper bound is that $\left(\rho_{k}\right)_{\alpha}^{U}=\max Z$ and the lower bound is $\left(\rho_{k}\right)_{\alpha}^{L}=\min Z$. We divide all the fuzzy decision units into three kinds by interval efficiency score under given $\alpha$ :

If the unit satisfies $\left(\rho_{k}\right)_{\alpha}^{L}=1$, then this unit is fuzzy DEA efficient under level $\alpha$;

If the unit satisfies $\left(\rho_{k}\right)_{\alpha}^{L}<1$ and $\left(\rho_{k}\right)_{\alpha}^{U}=1$ then this unit is part fuzzy DEA efficient under level $\alpha$; If the unit satisfies only $\left(\rho_{k}\right)_{\alpha}^{U}=1$ then this unit is part fuzzy DEA ineffective under level $\alpha$

\section{Empirical Research}

In this section, we use the data derived from ten commercial banks to analyze their efficiency with risk condition by SBM method and fuzzy SBM method, to check the merit of this fuzzy agorithm. Data are collected from annual reports of these banks during 2010 - 2014.Deposit, fixed asset, and operating expense are defined as the inputs, which are constant items; Bad loan ratio and capital adequancy ratio are regared as the outputs.

Firstly, scale merit(SM) analyzed by SBM model is shown in Table 1: 
Table 1

\begin{tabular}{|c|c|c|c|c|c|}
\hline & $\mathbf{2 0 1 0}$ & $\mathbf{2 0 1 1}$ & $\mathbf{2 0 1 2}$ & $\mathbf{2 0 1 3}$ & $\mathbf{2 0 1 4}$ \\
\hline & 0.935 & 0.919 & 0.93 & 0.945 & 0.95 \\
\hline Agricultural Bank of China & 0.943 & 0.965 & 0.974 & 0.98 & 1.000 \\
\hline Industrial and Commercial Bank of China & 0.925 & 0.979 & 0.963 & 0.982 & 0.98 \\
\hline Bank of China & 1.000 & 0.957 & 0.996 & 0.998 & 1.000 \\
\hline China Merchants Bank & 0.956 & 1.000 & 0.996 & 0.987 & 0.95 \\
\hline China CITIC Bank & 1.000 & 0.985 & 0.997 & 1.000 & 1.000 \\
\hline China Minsheng Bank & 0.964 & 0.973 & 0.98 & 0.956 & 0.932 \\
\hline Huaxia Bank & 1.000 & 1.000 & 1.000 & 1.000 & 1.000 \\
\hline Industrial Bank & 1.000 & 0.942 & 1.000 & 1.000 & 1.000 \\
\hline Pudong Development Bank & 1.000 & 1.000 & 1.000 & 1.000 & 1.000 \\
\hline PingAn Bank & &
\end{tabular}

Table 1 shows scale merit of ten commercial banks. Industrial Bank and PingAn Banks' efficiency seems to be always be 1 .efficiency change in the past five years can not been seen in the table above. So the fuzzy model is used in the following.

With the model above we fuzzy the net credit with the structure expression $\hat{L}=\left[L-L_{0}, L+L_{0}\right]$, in the expression $L$ means the net credit and $L_{0}$ means the overdue loan.

Afte compute efficiency value with SBM model, we try to get Interval-Value of technical efficiency based on different value of $\alpha$. The result is in Table 2

Table 2

\begin{tabular}{|c|c|c|c|c|c|c|c|}
\hline & & \multicolumn{6}{|c|}{ Fuzzy SBM } \\
\hline Bank & SBM & & $\alpha=0$ & $\alpha=0.3$ & $\alpha=0.5$ & $\alpha=0.7$ & $\alpha=1$ \\
\hline \multirow[t]{2}{*}{ Agricultural Bank of China } & \multirow[t]{2}{*}{0.65} & $\mathrm{~L}$ & 0.46 & 0.53 & 0.55 & 0.54 & 0.64 \\
\hline & & $\mathrm{U}$ & 1.00 & 1.00 & 0.86 & 0.67 & 0.54 \\
\hline \multirow{2}{*}{$\begin{array}{c}\text { Industrial and Commercial } \\
\text { Bank of China }\end{array}$} & \multirow[t]{2}{*}{1.00} & $\mathrm{~L}$ & 1.22 & 1.21 & 1.23 & 1.20 & 1.21 \\
\hline & & $\mathrm{U}$ & 1.23 & 1.22 & 1.24 & 1.22 & 1.22 \\
\hline \multirow[t]{2}{*}{ Bank of China } & \multirow[t]{2}{*}{1.00} & $\mathrm{~L}$ & 1.039 & 1.039 & 1.040 & 1.040 & 1.041 \\
\hline & & $\mathrm{U}$ & 1.042 & 1.041 & 1.041 & 1.041 & 1.041 \\
\hline \multirow[t]{2}{*}{ China Merchants Bank } & \multirow[t]{2}{*}{0.86} & $\mathrm{~L}$ & 0.25 & 0.37 & 0.46 & 0.58 & 0.89 \\
\hline & & U & 1.00 & 1.00 & 1.00 & 1.00 & 0.89 \\
\hline \multirow[t]{2}{*}{ China CITIC Bank } & \multirow[t]{2}{*}{1.00} & $\mathrm{~L}$ & 1.069 & 1.01 & 1.01 & 1.01 & 1.01 \\
\hline & & $\mathrm{U}$ & 1.152 & 1.04 & 1.03 & 1.02 & 1.01 \\
\hline \multirow[t]{2}{*}{ China Minsheng Bank } & \multirow[t]{2}{*}{0.842} & $\mathrm{~L}$ & 0.19 & 0.29 & 0.37 & 0.49 & 0.78 \\
\hline & & $\mathrm{U}$ & 1.00 & 1.00 & 1.00 & 1.00 & 0.78 \\
\hline \multirow[t]{2}{*}{ Huaxia Bank } & \multirow[t]{2}{*}{0.664} & $\mathrm{~L}$ & 0.07 & 0.14 & 0.19 & 0.27 & 0.66 \\
\hline & & $\mathrm{U}$ & 1.00 & 1.00 & 1.00 & 1.00 & 0.66 \\
\hline \multirow[t]{2}{*}{ Industrial Bank } & \multirow[t]{2}{*}{1.00} & $\mathrm{~L}$ & 1.05 & 1.09 & 1.12 & 1.15 & 1.20 \\
\hline & & $\mathrm{U}$ & 1.20 & 1.21 & 1.20 & 1.20 & 1.20 \\
\hline \multirow[t]{2}{*}{ Pudong Development Bank } & \multirow[t]{2}{*}{1.00} & $\mathrm{~L}$ & 1.01 & 1.02 & 1.02 & 1.02 & 1.03 \\
\hline & & $\mathrm{U}$ & 1.03 & 1.03 & 1.03 & 1.03 & 1.03 \\
\hline \multirow[t]{2}{*}{ PingAn Bank } & \multirow[t]{2}{*}{1.00} & $\mathrm{~L}$ & 1.01 & 1.04 & 1.07 & 1.13 & 1.49 \\
\hline & & U & 1.49 & 1.49 & 1.49 & 1.49 & 1.49 \\
\hline
\end{tabular}

From the table above, we acquire four banks' efficiency lower than 1, including $\mathrm{ABC}$, China Merchants Bank, China Minsheng Banking, and Huaxia Bank. They are SBM inefficient unit, while others are efficient.Then we use fuzzy SBM method to compute efficiency interval values under different $\alpha$ truncated set level including $0,0.3,0.5,0.7,1 . \alpha$ Truncate set level means different risk adjustments of inputs and outputs. The lower the set level, the large efficient change. That means the more risk bank faces, the large efficient changes.

From the intervel efficiency we can find out that risk factor influence efficiency differently among ten business banks. When $\alpha$ improved, the change of business efficiency become smaller, which means that the smaller risk banks face, the more stable the change. 
$\mathrm{ABC}$ and Huaxia are relatively inefficient with the efficient value 0.6500 and 0.6640 . That means these two are influnced by risk mostly, and they have the worst risk management. BC's efficiency is influenced smallest, which is 0.003 when $\alpha=0$, while Huaxia Bank's efficiency change range is 0.93, which is the largest. To sum up, sort the business bank by influence degree,increasely, is BC, ICBC, Pudong Development Bank, China CITIC Bank, Industrial Bank, PingAn Bank, ABC, China Merchants Bank, China Minsheng Bank, and Huaxia Bank. We can easily get the conclusion that BC'S risk management is the best, while Huaxia the worst.

Chen and Klien put forward interval evaluation in 1997, which is used to compute fuzzy index of business bank in the following table 3

\begin{tabular}{|c|c|c|c|c|}
\hline \multicolumn{1}{|c|}{ Bank } & $\begin{array}{c}\text { SBM } \\
\text { Efficiency }\end{array}$ & order & $\begin{array}{c}\text { Fuzzy SBM } \\
\text { Efficiency }\end{array}$ & order \\
\hline Agricultural Bank of China & 0.620 & 10 & 0.391 & 9 \\
\hline $\begin{array}{c}\text { Industrial and Commercial } \\
\text { Bank of China }\end{array}$ & 1.214 & 2 & 0.783 & 1 \\
\hline Bank of China & 1.043 & 4 & 0.640 & 4 \\
\hline ChinaMerchants Bank & 0.891 & 7 & 0.422 & 7 \\
\hline China CITIC Bank & 1.010 & 6 & 0.615 & 8 \\
\hline China Minsheng Bank & 0.842 & 8 & 0.401 & 10 \\
\hline Huaxia Bank & 0.663 & 9 & 0.352 & 3 \\
\hline Industrial Bank & 1.201 & 3 & 0.722 & 5 \\
\hline PudongDevelopment Bank & 1.032 & 5 & 0.622 & 2 \\
\hline PingAn Bank & 1.482 & 1 & 0.781 & \\
\hline
\end{tabular}

From the graph, we can find out PingAn is the most efficient business bank and when consider the risk, ICBC rank up to the first. When consider the risk factor, Huaxia drop to the last one.

\section{Conclusions}

In this paper a fuzzy slack-based model is developed to cope with uncertain conditions about inputs and outputs in the traditional ones. The new model can explain different conditions under different cut-sets.

Then we test the model with the example of commercial banks in China. Three conclusions are acquired in the empirical research.

Firstly, fuzzy controlled variables can been dealed with more efficiency and effectively with fuzzy SBM.

Moreover, the new model is under control when facing with data with difficulty in identification. Futhermore, efficiency of commercial banks have precise evaluations with fuzzy SBM. Efficiency of commercial banks is affected by risk. State-owned banks like Bank of China have better risk resistance than joint-stock banks like Huaxia Bank is also acquired.

\section{References}

[1] Li Ma, Junxun Dai and Xian Huang. Effect of capital constraints on risk preference behavior of commercial banks, China Finance Review International (2011)

[2]M.R. M ozaffari • J. Gerami • J. Jablonsky. Relationship between DEA models without explicit inputs and DEA-R models, Springer-Verlag Berlin Heidelberg(2012)

[3] Takashi Hasuike. Technical and Cost Efficiencies with Ranking Function in Fuzzy Data Envelopment Analysis. 2011 IEEE 978-1-61284-181-6/11

[4] Hsien-Chang Kuo, Lie-Huey Wang. Operating Pergraphance by the Development of Efficiency Measurement Based on Fuzzy DEA. 2007 IEEE 0-7695-2882-1/07

[5] Yi Zhang, Xian-jia Wang,Tender Evaluation Method for Engineering Projects Based on Modified DEA and Fuzzy Theory. 2010 IEEE 978-1-4244-5326-9/10 